\section{Doing Whole Earth justice: a reply to Cafaro et al.}

We are grateful to receive Cafaro et al.'s (2017) response to our article (Büscher et al., 2016). They clarify some of the principal tenets of the Nature Needs Half movement, and there are important issues we agree on. The outlook for biodiversity is bleak and we share a deep concern about this. Non-humans should be able to exist and thrive, and this is something that we also fully affirm. Equally important is the acknowledgement by Cafaro et al. that the neoliberal growth economy needs to be challenged if we are to make headway in addressing the extinction crisis. This position is significant given that it differs from that of the main champion of the Half Earth concept, E.O. Wilson (2016), who appears to have blind faith in the ability of free market capitalism to correct its social and environmental problems. It also opens up the potential for conservation to support efforts to resist the ravages of neoliberal capitalismsomething that has become more urgent in light of the Trump presidency (Büscher \& Fletcher, 2017).

Nevertheless, we remain unconvinced by the proposal to set aside half of the planet in protected areas. Cafaro et al. may be correct in saying this would save many species (although arguably only if the effects of climate change on biodiversity prove to be less severe than predicted). However, it will not address the destruction of nature that is fundamental to the global economy. Cafaro et al. acknowledge that setting aside half of the planet needs to be accompanied by an end to 'human misbehaviour' in the other half, but they offer no strategy for how to achieve this. We worry that focusing only on protected area expansion will make such changes less likely. It could distract from any search for mechanisms to redress an inherently unsustainable political economy or, worse, provide an excuse for doing nothing. This is why we argue for a Whole Earth vision. There are parallels here with the question of human population growth, raised by Cafaro et al. This is an important issue, but one that cannot be treated separately from the question of unequal levels of environmental impact. To do so provides a convenient rationale for focusing attention on the reproductive habits of the poor rather than the more environmentally damaging consumption habits of the rich.

Most significant is the human cost of the Half Earth proposal. Moving from c. $17 \%$ to $50 \%$ of the globe in protected areas across all biomes would have a tremendous social impact through processes of physical, economic and symbolic displacement. This could have desirable implications in some wealthier parts of the world (for example, through rewilding), but many of the new protected areas would be in places whose inhabitants have contributed least to the problem of global environmental change. It is all well to suggest that 'local communities should be actively involved in conservation efforts', but what power will their interests, voices and rights have in the face of the claims of supporters of the Nature Needs Half movement? The lack of a clear and operationalized commitment to global justice is a profound flaw in the Nature Needs Half vision.

Setting aside half of the planet does not help us learn how to live with nature (Turnhout et al., 2013) in an unjust world. Rather, it exacerbates already problematic nature/culture dichotomies that are at the heart of the problem of extinction of species, and of the neoliberal growth economy. Without a definite plan for how to address either the human costs of the Nature Needs Half proposal or continued threats from the global economy to the non-human species in whose name it is promoted, we remain deeply concerned by the implications of such a proposal. We believe we need a Whole Earth approach that explores new ways for humans and non-humans to live together within an economy that promotes prosperity without the need for narrow economic growth.

BRAM BÜSCHER (Corresponding author) and ROBERT FLETCHER Wageningen University, Wageningen, The Netherlands E-mailbram.buscher@wur.nl

DAN BROCKINGTON Sheffield Institute of International
Development, Sheffield, UK

Chris SANDBROoK and BILL AdAMs University of Cambridge, UK

LISA CAMPBELL Duke University Marine Lab, Beaufort, USA

Catherine Corson Mount Holyoke College, South Hadley, Massachusetts, USA

Wolfram Dressler University of Melbourne, Australia

ROSALEEN DUFFY University of Sheffield, UK

NoElla Gray University of Guelph, Ontario, Canada

GeORge Holmes University of Leeds, UK

ALICE KeLLY University of California Berkeley, USA

Elizabeth Lunstrum York University, Toronto, Canada

Maano Ramutsindela University of Cape Town, South Africa

KARTIK SHANKER Ashoka Trust for Research in Ecology and the Environment, Bangalore, India; Dakshin Foundation, Bangalore, India; and Indian Institute of Science, Bangalore, India

\section{References}

Búscher, B. \& Fletcher, R. (2017) The Trump moment in environmental conservation. Https://entitleblog.org/2017/02/02/ the-trump-moment-in-environmental-conservation/ [accessed 28 February 2017].

Büscher, B., Fletcher, R., Brockington, D., Sandbrook, C., Adams, W., Camp bell, L. et al. (2016) Half-Earth or Whole Earth? Radical ideas for conservation, and their implications. Oryx, https:// doi.org/10.1017/So030605316001228.

Cafaro, P., Butler, T., Crist, E., Cryer, P., Dinerstein, E., Kopnina, H. et al. (2017) If we want a whole Earth, Nature Needs Half: a response to Büscher et al. Oryx, https://doi.org/10.1017/ Soo30605317000072.

Turnhout, E., Waterton, C., Neves, K. \& Buizer, M. (2013) Rethinking biodiversity: from goods and services to "living with". Conservation Letters, 6, 154-161.

Wilson, E.O. (2016) Half-Earth. Our Planet's Fight for Life. Liveright Publishing, London, UK. 